\title{
Comparative Transcriptome Analysis of Gill Tissue in Response to Hypoxia in Silver Sillago (Sillago sihama)
}

\author{
Wanida Saetan $1,2,+\oplus$, Changxu Tian $1,2,+\left(\mathbb{D}\right.$, Jiawang $\mathrm{Yu}^{1}$, Xinghua Lin ${ }^{1,2}$, Feixiang $\mathrm{He}^{1,2}$, \\ Yang Huang ${ }^{1,2,3}$, Hongjuan Shi ${ }^{1,2,3}$, Yulei Zhang ${ }^{1,2,3}$ and Guangli Li 1,2,3,*(D) \\ 1 Fisheries College, Guangdong Ocean University, Zhanjiang 524088, China; wanidamnk62@gmail.com (W.S.); \\ tiancx@gdou.edu.cn (C.T.); yjw9902122020@163.com (J.Y.); lxh_13414934257@163.com (X.L.); \\ fly476806029@gmail.com (F.H.); zjouhy@126.com (Y.H.); shihongjuan1990@163.com (H.S.); \\ yuleizhang88@163.com (Y.Z.) \\ 2 Guangdong Research Center on Reproductive Control and Breeding Technology of Indigenous Valuable Fish \\ Species, Zhanjiang 524088, China \\ 3 Marine Ecology and Aquaculture Environment of Zhanjiang, Zhanjiang 524088, China \\ * Correspondence: ligl@gdou.edu.cn; Tel.: +86-759-2383124; Fax: +86-759-2382459 \\ + These authors contributed equally to this work.
}

Received: 12 February 2020; Accepted: 5 April 2020; Published: 6 April 2020

Simple Summary: Silver sillago (Sillago sihama) is a marine fish species with a high economic value. S. sihama is poorly resistant to hypoxia. However, hypoxia stress-related genes and pathways in S. sihama remain unclear. In this study, we compared gill tissues of $S$. sihama between hypoxia and normoxia groups and detected differentially expressed genes under hypoxia stress. Two gene families, such as cytochrome P450 and glutathione S-transferase were associated with the function of metabolic process under the hypoxia stress. This study will expand our knowledge about the molecular mechanism of the transcriptome response to hypoxia stress in S. sihama.

\begin{abstract}
Silver sillago (Sillago sihama) is a commercially important marine fish species in East Asia. In this study, we compared the transcriptome response to hypoxia stress in the gill tissue of S. sihama. The fish were divided into four groups, such as $1 \mathrm{~h}$ of hypoxia (hypoxia1h, DO $=1.5 \pm 0.1 \mathrm{mg} / \mathrm{L}$ ), $4 \mathrm{~h}$ of hypoxia (hypoxia4h, DO $=1.5 \pm 0.1 \mathrm{mg} / \mathrm{L}$ ), $4 \mathrm{~h}$ of reoxygen (reoxygen $4 \mathrm{~h}, \mathrm{DO}=8.0 \pm 0.2 \mathrm{mg} / \mathrm{L}$ ) after $4 \mathrm{~h}$ of hypoxia $(\mathrm{DO}=1.5 \mathrm{mg} / \mathrm{L})$, and normoxia or control $(\mathrm{DO}=8.0 \pm 0.2 \mathrm{mg} / \mathrm{L})$ groups. Compared to the normoxia group, a total of 3550 genes were identified as differentially expressed genes (DEGs) ( $\log _{2}$ foldchange $>1$ and padj < 0.05), including 1103, 1451 and 996 genes in hypoxia $1 \mathrm{~h}$, hypoxia4h and reoxygen 4 h groups, respectively. Only 247 DEGs were differentially co-expressed in all treatment groups. According to Kyoto Encyclopedia of Genes and Genomes (KEGG) pathway analysis, DEGs were significantly enriched in steroid biosynthesis, biosynthesis of amino acids, glutathione metabolism and metabolism of xenobiotics by cytochrome P450, ferroptosis and drug metabolism-cytochrome P450 pathways. Of these, the cytochrome P450 (CYP) and glutathione S-transferase (GST) gene families were widely expressed. Our study represents the insights into the underlying molecular mechanisms of hypoxia stress.
\end{abstract}

Keywords: Sillago sihama; hypoxia stress response; gene expression; RNA-Seq

\section{Introduction}

Hypoxia is one of the most significant stressors for most aquatic animals, which affects the development of aquaculture. Hypoxia refers to a dissolved oxygen (DO) level of less than $2.0 \mathrm{mg} / \mathrm{L}$ in 
the aquatic environment, which can be accelerated by several factors, such as human activities, water pollution, and intensive fish farming [1]. To adapt to the hypoxic environment, fish produce a range of adaptive physiological mechanisms, such as a rapid change in cell metabolism using ATP [2], regulation of respiratory function [3], floating head [4], and neurological, immune, and hormonal responses [5]. Severe hypoxia can even affect fish reproduction, survival, and cell metabolism [6]. The fish gill is the primary organ for physiological exchanges with the surrounding environment [7]. The fish gill plays a dominant role in aquatic gas exchange and is capable of extensive remodeling in response to changes in the DO level [8]. Many fish respond to hypoxia by increasing the functional surface area of their gill [4]. When the fish returns to normoxic water, the hypoxia-induced gill remodeling is reversed due to the embedding of gill lamellae [9].

The sillago silver (Sillago sihama) is a popular species of the family Sillaginidae [10]. S. sihama is a tropical shallow-water fish species, which is widely distributed in the Indian Ocean and along the coasts of China, Korea, and Japan. It is known as one of the commercially important fish species in East Asia [11,12]. The population of S. sihama has dramatically reduced due to overfishing and environmental pollution [12]. Therefore, it is necessary to increase the yield of this fish species by artificial breeding. However, it is difficult to breed S. sihama by artificial breeding programs due to its hypoxia sensitivity, which causes fish mortality, especially during the first week of the larval stage [13].

Next-generation sequencing (NGS) technology has been widely used to determine the gene expression levels in different organisms [14]. Based on Illumina sequencing technology, researchers have identified a number of hypoxia stress-related genes and signaling pathways in several aquatic organisms, such as schizothoracine fish (Gymnocypris eckloni) [15], hooded seal (Cystophora cristata) [16], blunt snout bream (Megalobrama amblycephala) [17], channel catfish (Ictalurus punctatus) [18], crucian carp (Carassius auratus) [19], Nile tilapia (Oreochromis niloticus) [20], zebrafish (Danio rerio) [21] and Atlantic salmon (Salmo salar) [22]. Although a number of hypoxia stress-related genes and pathways have been identified in fish, the molecular mechanisms related to hypoxia response vary in different species.

To date, there is scant information on hypoxia stress-related genes and no report on transcriptome response to hypoxia stress observed in S. sihama. Therefore, the study aimed to examine the transcriptome response to hypoxia stress in S. sihama using RNA-seq technology. The transcriptome profiles of the gill tissues between hypoxia and normoxia were compared and analyzed by detecting differentially expressed genes under hypoxia stress and the interactions of their pathways. This study will expand our knowledge about the molecular mechanism of the transcriptome response to hypoxia stress in S. sihama.

\section{Materials and Methods}

\subsection{Ethical Statements}

All experimental protocols were approved by the Animal Research and Ethics Committee of Guangdong Ocean University (201903003).

\subsection{Fish and Hypoxia Experiment}

S. sihama (13.40 $\pm 1.05 \mathrm{~cm}$ of total length and $14.57 \pm 3.17 \mathrm{~g}$ of body weight) were obtained from Donghai Island, Guangdong, China. Before the experiment, 100 individuals were selected for hypoxia stress pre-experiment. According to pre-experiment, the average asphyxiation point was $1.0 \mathrm{mg} / \mathrm{L}$ and the floating head phenomenon was $1.5 \mathrm{mg} / \mathrm{L}$. In addition, 200 individuals were collected and transferred to four $50 \mathrm{~L}$ tanks with a bio-filtered water recirculation system. After the acclimation at $25 \pm 1{ }^{\circ} \mathrm{C}$ temperature, $8.0 \mathrm{mg} / \mathrm{L}$ dissolved oxygen (DO) (normoxia) and $29 \%$ o salinity, the experiments were conducted in a bio-filtered water recirculation system for 1 month. During the acclimation period, the fish were fed with a commercial diet twice per day. The water quality was checked every day, and the dead animals and particles were removed at once. 
Healthy fish were randomly transferred to four aquarium tanks (50 L) at a density of 50 fish per tank. Each tank has $40 \mathrm{~L}$ of seawater $\left(25 \pm 1^{\circ} \mathrm{C}\right.$ temperature and $29 \%$ o salinity). The concentration of DO was measured each hour interval by JPB-607A dissolved oxygen meter (INESA Scientific Instrument Co. Ltd., Shanghai, China). The experimental fish were divided into four groups, including hypoxia for $0 \mathrm{~h}$ (normoxia, $\mathrm{DO}=8.0 \pm 0.2 \mathrm{mg} / \mathrm{L}$ ), hypoxia for $1 \mathrm{~h}$ (hypoxia1h, $\mathrm{DO}=1.5 \pm 0.1 \mathrm{mg} / \mathrm{L}$ ), hypoxia for $4 \mathrm{~h}$ (hypoxia4h, $\mathrm{DO}=1.5 \pm 0.1 \mathrm{mg} / \mathrm{L}$ ) and normal oxygen recovered in $4 \mathrm{~h}$ after hypoxia4h (reoxygen4h, $\mathrm{DO}=8.0 \pm 0.2 \mathrm{mg} / \mathrm{L})($ Table S1). In hypoxia group, pure nitrogen was added to reduce the DO level in the tank of the hypoxia group from $(8.0 \pm 0.2) \mathrm{mg} / \mathrm{L}$ to $(1.5 \pm 0.1) \mathrm{mg} / \mathrm{L}$ and maintain the DO level $(1.5 \pm 0.1 \mathrm{mg} / \mathrm{L})$ in the water. After $1 \mathrm{~h}$ and $4 \mathrm{~h}$ of hypoxia stress, ten floating fish were selected for sampling from hypoxia $1 \mathrm{~h}$ and hypoxia $4 \mathrm{~h}$ groups, respectively. From normoxia and reoxygen $4 \mathrm{~h}$ groups, 10 normal swimming fish per group were selected for sampling. All fish were anesthetized in a eugenol bath (1:1000). Fish gill samples from each group were taken, immediately frozen in liquid nitrogen and stored at $-80{ }^{\circ} \mathrm{C}$ for further analysis.

\subsection{RNA Extraction and Illumina Library Preparation}

The total RNA of gill ( $\mathrm{n}=3$ per group) from the four groups was extracted using TRIzol reagent (Life Technologies, Carlsbad, CA, USA) following the manufacturer's instructions. The RNA purity was monitored by NanoPhotometer spectrophotometer (Nanodrop 2000c, Thermo Scientific, Wilmington, DE, USA). The RNA integrity was checked by ethidium bromide staining of $28 \mathrm{~S}$ and $18 \mathrm{~S}$ ribosomal bands on a $1.0 \%$ agarose gel.

A total of $3 \mu \mathrm{g}$ RNA was prepared for each Illumina library sequence. Sequencing libraries were generated using the NEBNext ${ }^{\circledR}$ Ultra $^{\mathrm{TM}}$ RNA Library Prep Kit for Illumina ${ }^{\circledR}$ (NEB, Carlsbad, CA, USA) following the manufacturer's instructions. The library fragments were purified using the AMPure XP system (Beckman Coulter, Beverly, MA, USA) to select 250-300 bp complementary DNA (cDNA) fragments and each library quality was assessed by the Agilent Bioanalyzer 2100 system (Agilent Technologies, CA, USA). Then, $3 \mu \mathrm{L}$ of USER Enzyme (NEB, USA) was used with size-selected, adaptor-ligated $\mathrm{cDNA}$ at $37^{\circ} \mathrm{C}$ for $15 \mathrm{~min}$, followed by $5 \mathrm{~min}$ at $95^{\circ} \mathrm{C}$ before PCR. PCR was performed with Phusion High-Fidelity DNA polymerase, universal PCR primers and Index (X) Primer. Finally, PCR products were purified by the AMPure XP system and library quality was assessed by the Agilent Bioanalyzer 2100 system. All clean libraries of sequencing data were submitted to the NCBI Sequence Read Archive (SRA) database (Accession No.: SRR9673344 - SRR9673355).

\subsection{Data Filtering, Reads Mapping and Differential Expression Analysis}

Based on the S. sihama reference genome and gene model annotation files (unpublished data), the index and paired-end of clean reads were established by Hisat2 v2.0.5 (https://anaconda.org/ biobuilds/hisat2). The total number of reads was mapped to each gene using featureCounts v1.5.0-p3. The fragments per kilobase of exon model per million reads mapped (FPKM) was used to estimate the expressed gene levels [23]. Raw data (raw reads) in fastq format were processed through in-house perl scripts. Clean data (clean reads) were obtained by removing reads containing adapter, poly-N and low-quality reads from raw data. The Q20, Q30, and GC-content of the clean data were calculated.

Differentially expressed genes (DEGs) between the normoxia and hypoxia treatments were identified using DESeq2 R package (version 1.16.1) [24]. DESeq2 provides statistical routines for determining differential expressions in digital gene expression data using a model based on the negative binomial distribution [25]. The threshold for identifying significant DEGs was set to adjusted $p$-value (padj) $<0.05$ and $\mid \log _{2}$ fold change $>1.0$. DEGs were then subjected to enrichment analysis of Gene Ontology (GO) functions, KEGG pathways and those with $p<0.05$ were considered significantly enriched. 


\subsection{Validation of DEGs by Quantitative Real-Time Polymerase Chain Reaction (qRT-PCR)}

To verify the validity of the DEGs from RNA-seq data, 14 DEGs were selected randomly for examination by the qRT-PCR. The first-strand cDNA was synthesized using the PrimeScript ${ }^{\mathrm{TM}} \mathrm{RT}^{\mathrm{T}}$ reagent kit with gDNA Eraser (Takara, China) using $1 \mu \mathrm{g}$ of total RNA.The reaction mixture $20 \mu \mathrm{L}$ of each sample contained $10 \mu \mathrm{L} 2$ X SYBR Green MasterMix reagent (Toyobo, Japan), $2 \mu \mathrm{L}$ of 1:10 diluted cDNA with double-distilled water (DDW), $6.4 \mu \mathrm{L}$ DDW, and $0.8 \mu \mathrm{L}$ of each primer $(10 \mu \mathrm{mol} / \mathrm{L})$. The qRT-PCR primers were designed by Primer v6.0 as listed in Table S2. The PCR conditions were carried out as follows: initial denaturation at $95^{\circ} \mathrm{C}$ for $5 \mathrm{~min}$, followed by 32 cycles of $30 \mathrm{~s}$ denaturation at $94{ }^{\circ} \mathrm{C}$, annealing at $60{ }^{\circ} \mathrm{C}$ for $30 \mathrm{~s}$ and extension at $72{ }^{\circ} \mathrm{C}$ for $20 \mathrm{~s}$. To standardize gene expression values, the ribosomal protein L7 ( $r p l 7)$ gene was used as a reference [26]. The relative expression levels of DEGs were analyzed using the $2^{-\Delta \Delta C T}$ method [27]. The statistical analysis was performed using SPSS v19.0.

\section{Results and Discussion}

\subsection{Illumina Sequencing Assembly}

We constructed 12 cDNA libraries from four groups with triplicates (Table 1). The raw reads in each library ranged from $42,655,494$ to 59,525,298. After removing and filtering adapter, poly-N and low quality reads, a total of 553,591,836 clean reads were obtained. The number of clean reads, including 146,129,138 reads in hypoxia1h group, 146,054,350 reads in hypoxia4h group, 138,170,114 reads in reoxygen 4 h group and 123,238,234 reads in normoxia group with Q20 (96.24\%-97.23\%) and Q30 (90.38\%-92.80\%) levels were obtained (Table 1).

Table 1. Summary of gill transcriptome sequencing data.

\begin{tabular}{ccccccc}
\hline Group & Raw Reads & Clean Reads & Clean Bases (G) & Q20 (\%) & Q30 (\%) & GC Content (\%) \\
\hline Hypoxia1hr. & & & & & & \\
G_HI_1 & $59,525,298$ & $57,377,574$ & 8.61 & 97.00 & 92.30 & 47.58 \\
G_HI_2 & $45,730,892$ & $43,973,742$ & 6.60 & 96.24 & 90.38 & 46.97 \\
G_HI_3 & $48,080,268$ & $44,777,822$ & 6.72 & 96.87 & 92.04 & 46.98 \\
Hypoxia4hr. & & & & & & \\
G_HT_1 & $48,635,558$ & $46,533,572$ & 6.98 & 96.32 & 90.58 & 47.03 \\
G_HT_2 & $49,539,404$ & $47,922,836$ & 7.19 & 96.94 & 92.18 & 47.52 \\
G_HT_3 & $53,859,006$ & $51,597,942$ & 7.74 & 96.91 & 92.17 & 46.87 \\
Reoxygen4hr. & & & & & & 46.63 \\
G_RO_1 & $47,007,630$ & $44,659,448$ & 6.70 & 96.59 & 91.37 & 46.78 \\
G_RO_2 & $46,031,644$ & $43,741,284$ & 6.56 & 97.16 & 92.57 & 47.32 \\
G_RO_3 & $52,813,132$ & $49,769,382$ & 7.47 & 96.58 & 91.37 & \\
Normoxia & & & & & & 47.31 \\
G_NO_1 & $42,655,494$ & $40,115,434$ & 6.02 & 97.23 & 92.8 & 48.49 \\
G_NO_2 & $43,073,570$ & $41,127,670$ & 6.17 & 96.8 & 91.79 & \\
G_NO_3 & $44,331,564$ & $41,995,130$ & 6.30 & 96.75 & 91.75 & \\
\hline
\end{tabular}

\subsection{Differential Gene Expression Analysis}

A total of 3550 genes were identified as DEGs (Figure 1A). Compared to the normoxia group, 1,103 DEGs were detected in the hypoxia1h group, of which 664 DEGs were up-regulated and 439 DEGs were down-regulated. In the hypoxia4h group, a total of 1451 DEGs were identified, including 765 up-regulated and 686 down-regulated genes. In the reoxygen4h group, 996 DEGs were identified, including 419 up-regulated and 577 down-regulated genes (Figure 1A). Among these, the top ten upand down-regulated annotated genes were presented in Table S3. 


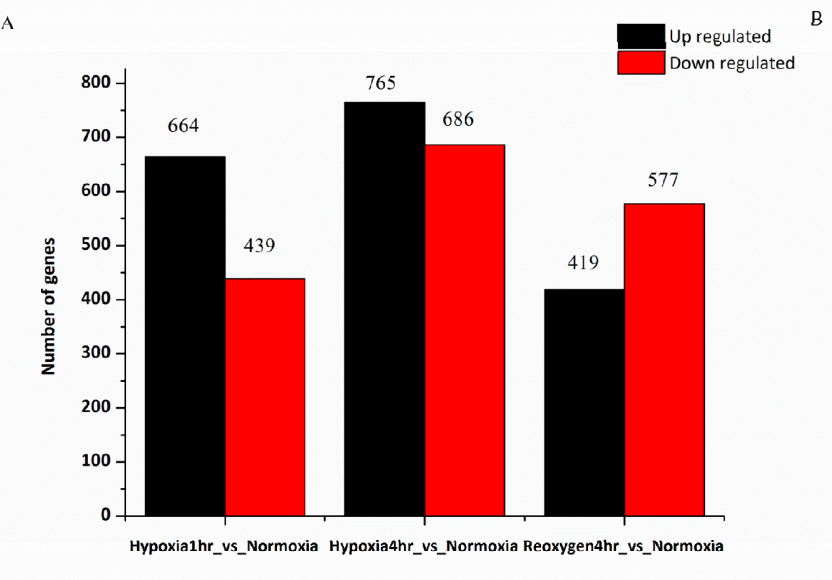

B Hypoxia1hr_vs_Normoxia Hypoxia4hr_vs_Normoxia

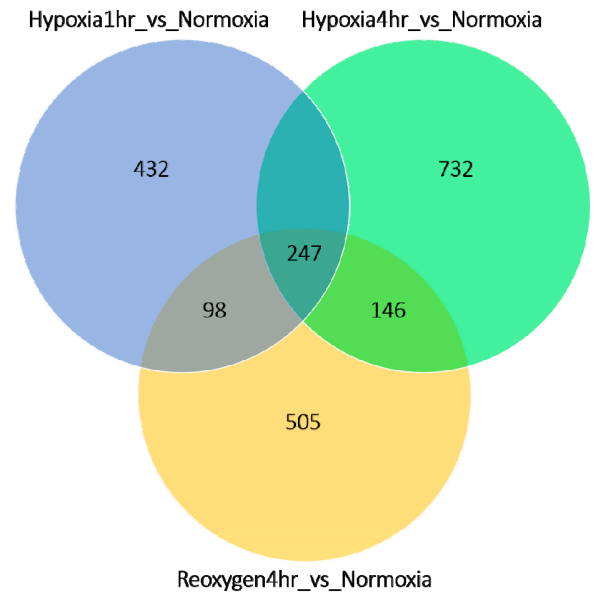

Figure 1. Different expression profiles. Notes: (A) The number of up- and down-regulated differentially expressed genes (DEGs) in each comparison group; (B) Venn diagram of all DEGs under hypoxia1h, hypoxia4h and reoxygen4h compared to normoxia group. Genes expressed only in hypoxia1h group (yellow circle); genes expressed only in hypoxia4h group (light blue circle); genes expressed only in reoxygen4h group (light purple circle). ( $\log _{2}$ foldchang $>1.0$ and padj $<0.05$ ).

A Venn diagram analysis showed that 247 DEGs were co-expressed in all three treatment groups (hypoxia1h, hypoxia4h and reoxygen $4 \mathrm{~h}$ ) (Figure 1B). Of these, 247 genes were co-expressed in all treatment groups, and insulin-like growth factor (igfbp1) and hypoxia-inducible factor prolyl hydroxylase $(e g \ln 3)$ were down-regulated at reoxygen4h group but up-regulated in hypoxia1h and hypoxia4h groups (Table 2). A total of 432, 732, and 505 DEGs were expressed specifically in hypoxia1h, hypoxia4h and reoxygen4h groups, respectively, and 326, 146 and 98 genes were co-expressed in hypoxia $1 \mathrm{~h}$ and hypoxia $4 \mathrm{~h}$, hypoxia $4 \mathrm{~h}$ and reoxygen $4 \mathrm{~h}$, and reoxygen $4 \mathrm{~h}$ and hypoxia $1 \mathrm{~h}$ groups, respectively.

Table 2. Annotation of the top ten differential expression genes in three treatment groups (padj < 0.05$)$.

\begin{tabular}{|c|c|c|c|c|}
\hline \multirow{2}{*}{$\begin{array}{l}\text { Gene } \\
\text { Name }\end{array}$} & \multicolumn{3}{|c|}{$\log _{2}$ (Fold Change) } & \multirow{2}{*}{ Description } \\
\hline & Hypoxia1h & Hypoxia4h & Reoxygen $4 \mathrm{~h}$ & \\
\hline gimap4 & 6.39 & 6.45 & 6.89 & GTPase IMAP family member 4 \\
\hline tekt3 & 6.39 & 5.79 & 4.27 & Tektin-3 \\
\hline hisat & 5.10 & 4.38 & 3.12 & Histidine N-acetyltransferase \\
\hline kcnq2 & 4.23 & 4.27 & 4.44 & Potassium voltage-gated channel subfamily KQT r 2 \\
\hline egln 3 & 3.86 & 6.21 & -1.16 & Hypoxia-inducible factor prolyl hydroxylase \\
\hline aqp9 & 3.19 & 2.83 & 3.57 & Aquaporin-9 \\
\hline slc12a3 & 3.12 & 1.67 & -1.68 & Solute carrier family 12 member 3 \\
\hline igfbp1 & 1.90 & 1.80 & -1.17 & Insulin-like growth factor-binding protein 1 \\
\hline pde4 & 1.36 & 1.89 & -1.26 & cAMP-specific phosphodiesterase 4 \\
\hline pck1 & 1.32 & 1.05 & -1.06 & Phosphoenolpyruvate carboxykinase (GTP) \\
\hline bmp10 & 1.57 & 2.19 & -1.88 & bone morphogenetic protein 10 \\
\hline trim16 & 1.17 & 2.05 & -1.31 & Tripartite motif-containing protein 16 \\
\hline$k c n k 1$ & 1.07 & 1.52 & -1.32 & Potassium channel subfamily K member 1 \\
\hline cxcr 4 & 1.19 & 1.07 & -1.69 & C-X-C chemokine receptor type 4 \\
\hline$p 4 h b$ & -6.47 & -3.99 & -6.60 & Protein disulfide-isomerase \\
\hline$t x \_B$ & -4.21 & -4.59 & -2.75 & Tx beta-subunit \\
\hline glipr2 & -4.15 & -1.58 & -3.73 & Golgi-associated plant pathogenesis-related protein 1 \\
\hline gimap7 & -4.08 & -4.95 & -3.16 & GTPase IMAP family member 7 \\
\hline endod1 & -3.57 & -3.61 & -4.53 & Endonuclease domain-containing 1 protein \\
\hline
\end{tabular}




\subsection{GO Term Enrichment Analysis}

In this study, all DEGs in each treatment group were enriched in GO and classified into three categories, including biological process (BP), cellular component (CC) and molecular function (MF). Two GO terms in MF categories were significantly enriched in the reoxygen4h group, including "nucleic acid-binding transcription factor activity" (GO:0001071) and "transcription factor activity, sequence-specific DNA binding" (GO:0003700) (Figure 2C). In contrast, no GO term was significantly enriched in the hypoxia1h and hypoxia4h groups (Figure 2A,B).
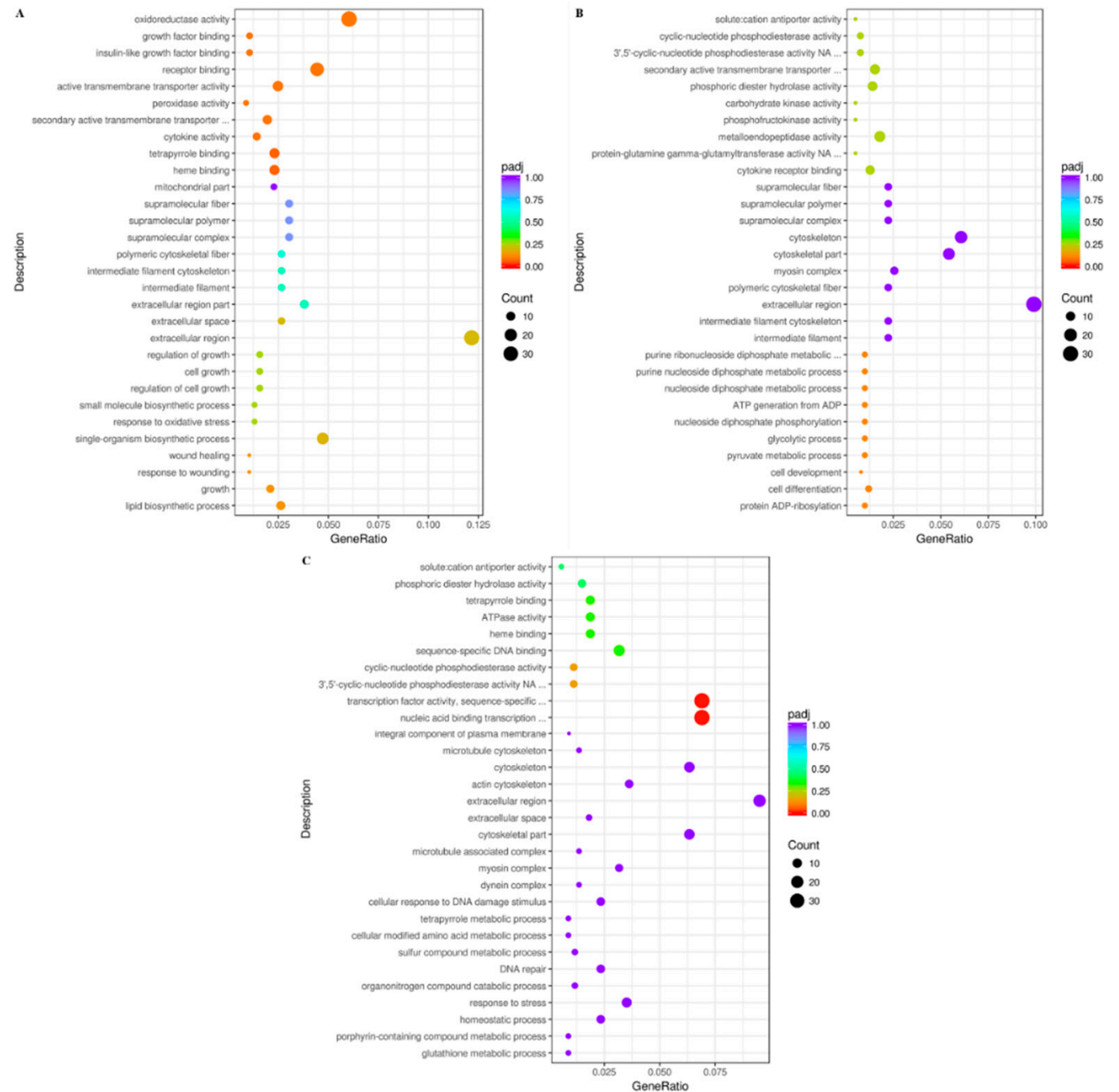

Figure 2. GO function classification of the differentially expressed genes (DEGs) comparison between the groups (padj < 0.05). (A) hypoxia1h_vs_normoxia, (B) hypoxia4h_vs_normoxia, (C) reoxygen4h_vs_normoxia. The $x$-axis represents the number of genes and the $y$-axis represents different Gene Ontology (GO) term functional classification.

Compared to the normoxia group, the up-regulated DEGs were significantly enriched in 7 and 16 GO terms under hyoxia1h and the hyoxia4h groups, respectively (Table S4). However, no down-regulated DEG was significantly enriched in any GO under hypoxia1h and hyoxia4h groups (Table S4). In addition, down-regulated DEGs were significantly enriched in 4 GO terms under the reoxygen 4 h group (Table $\mathrm{S} 4$ ).

\subsection{KEGG Pathway Enrichment Analysis}

KEGG enrichment pathways were identified from DEGs. There were two KEGG pathways, including steroid biosynthesis pathway and biosynthesis of amino acid pathway, which were 
significantly enriched in the hypoxia1h group (Figure S1A). The steroid biosynthesis pathway was also significantly enriched in the hypoxia4h group (Figure S1B). In the reoxygen4h group, four enriched KEGG pathways were identified, including glutathione metabolism, metabolism of xenobiotics by cytochrome P450, drug metabolism cytochrome P450 and ferroptosis pathways (Figure S1C). All significantly enriched KEGG pathways and DEGs were shown in Table 3.

Table 3. Significantly enriched Kyoto encyclopedia of genes and genomes (KEGG) pathways of differentially expressed genes (DEGs) in hypoxia1h_vs_normoxia, hypoxia4h_vs_normoxia and reoxygen4h_vs_normoxia group (padj < 0.05).

\begin{tabular}{|c|c|c|}
\hline Pathway ID & Pathway Term & Gene Name \\
\hline & Hypoxia1hr_vs_Normoxia & \\
\hline dre00100 & Steroid biosynthesis & $\begin{array}{l}\text { meso1, cyp51, sqle, } n s d h l, t m 7 s f 2, f d f t 1, \\
\text { dhcr } 24, \text { dhcr } 7, l s s, \text { ebp }\end{array}$ \\
\hline \multirow[t]{2}{*}{ dre01230 } & Biosynthesis of amino acids & $\begin{array}{c}\text { pk, aldo, phgdh, pfk, aco, gln } A, p g a m, c p s 1, \\
\text { ass1, tkt } A, t k t B, i d h 1 \text { idh2 }\end{array}$ \\
\hline & Hypoxia4hr_vs_Normoxia & \\
\hline \multirow[t]{2}{*}{ dre00100 } & Steroid biosynthesis & $\begin{array}{c}\text { meso1, tm7sf2, sqle, dhcr24, lss, nsdhl, cyp51, } \\
\text { fdft1, cyp24a1 }\end{array}$ \\
\hline & Reoxygen4hr_vs_Normoxia & \\
\hline dre00480 & Glutathione metabolism & $\begin{array}{l}\text { gclc, gsto1, gsr, LOC108897969, gss, gclm, } \\
\text { gst, g6pd, LOC104939687, LOC104921330 }\end{array}$ \\
\hline dre00980 & Metabolism of xenobiotics by cytochrome P450 & $\begin{array}{c}\text { gsto1, LOC108897969, cbr1, gst, cyp1a1, } \\
\text { LOC104939687, ugt1a1 }\end{array}$ \\
\hline dre04216 & Ferroptosis & $g c l c, f t h 1, g s s, g c l m, t f, h m o x 1, t f r c$ \\
\hline dre00982 & Drug metabolism - cytochrome P450 & $\begin{array}{c}\text { gsto1, LOC108897969, gst, LOC104939687, } \\
\text { ugt1a1 }\end{array}$ \\
\hline
\end{tabular}

\subsection{Validation of RNA-Seq Data with $q R T-P C R$}

The results showed that the gene expression patterns of the two methods were consistent (Figure 3), indicating that the specific and accuracy of the transcriptome expression analysis. Among these, the fold induction values of hif2a, $r d h 8$ and epo genes showed significant differences between the treatment groups.

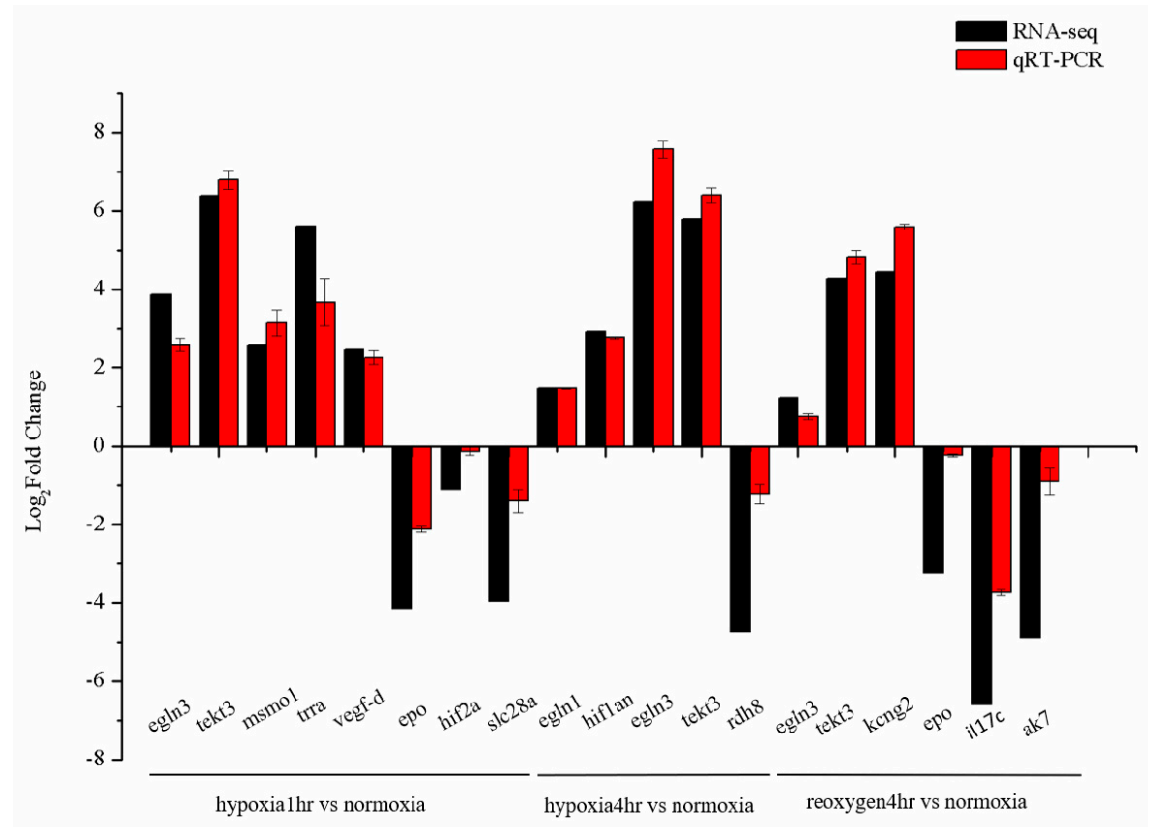

Figure 3. Comparison of gene expression data between RNA-seq and quantitative real-time PCR (qRT-PCR). The $x$-axis presents the gene name and the $y$-axis presents fold change in gene expression. 


\subsection{DEGs as Adaptive Response to Hypoxia}

Globally, hypoxia is one of the major causes of economic loss in the aquaculture industry. In teleosts, gill is the first organ that responds to rapid changes in the DO level of water. Hypoxia disrupts the normal functions of the gill, including osmoregulation, respiration and nitrogenous waste excretion [28]. Therefore, the study about transcriptome response to hypoxia stress in gill tissue has significance.

In this study, we identified DEGs and their expression patterns under hypoxia stress in S. sihama. A previous study reported that the number of DEGs was increased with the increase of exposure time to hypoxia [29]. More DEGs up-regulated than down-regulated, which were also observed in other fish [29,30], indicated increasing gene expression levels as a major response for adaptation to hypoxic environments.

By comparing the three hypoxia treatment groups, genes involved in oxidative stress and immune response were significantly differentially expressed under hypoxia stress (Table 2). As a reported hypoxia-related gene in fish, egln3 acts as a key factor to inhibit or stabilize hypoxia inducible factor alpha (HIF-1) under hypoxia [31]. Igfbp-1 gene regulates the production of reactive oxygen species (ROS) in oxidative stress. Up-regulation of these genes were also observed in freshwater fish $[15,32]$. In addition, the gimap4 and gimap7 genes were significantly differentially expressed under hypoxia, and similar results were also observed in other fish [33,34]. The GTPase IMAP (gimaps) gene family regulate cell apoptosis and development and has a conserved function in the immune system of vertebrates $[35,36]$, indicating that fish may respond positively to the hypoxic environments by regulating the immune response system mediated by the imaps gene family.

The CYP superfamily plays a critical role in the oxidative metabolism and the main enzyme is responsible for biosynthetic processes in the organism, such as steroid hormones, sterols and and vitamins [37,38]. In the present study, the up-regulated cytochrome P450 family 51 (cyp51) and cytochrome P450 family 24A1 (cyp24a1) genes were significantly enriched in the steroid biosynthesis pathway under hypoxia. The cyp51 is a key factor of sterol biosynthetic pathways [39], which is regulated by cholesterol. This gene was involved in the reproduction and development in fish [40-42]. Cyp24a1 plays a vital role in the metabolism and catabolism of vitamin D [43-45]. In this study, the up-regulated cytochrome P450 family 1A (cyp1a) gene was significantly enriched in the reoxygen4h group. The cyp1a gene family contains cyp1a1 and cytochrome P450 family 1A2 (cyp1a2) subfamilies in mammals and other tetrapods [46]. Previous studies have reported that cyp1 displayed similar expression responses to environmental stress in aquatic animals $[47,48]$. The cyp1 is involved in detoxifying the functions of environmental pollutants. Chronic intermittent hypoxia (CIH) decreased the expression of the hepatic cyp1a2 gene in the drug metabolisom process of mouse [49].

The KEGG enrichment analysis showed that glutathione metabolism and metabolism of xenobiotics by CYPs were significantly enriched in the reoxygen4h group. The glutamate and glutamine genes, such as glutamate-cysteine ligase catalytic subunit $(g c l c)$, glutamate-cysteine ligase regulatory subunit $(g c l m)$, glutathione synthetase $(g s s)$ and glucose 6 phosphate 1 dehydrogenase $(g 6 p d)$, were significantly differentially expressed in different treatment groups under hypoxic stress, indicating that the glutamate and glutamine gene families play an important role in transcriptional regulation of hypoxia.Glutathione maintains normal immune system function and has antioxidant effects. Among them, the $g c l c, g c l m$ and $g s s$ were synthase and rate-limiting enzyme in glutathione. The main function of the $g 6 p d$ gene is to produce NADPH, which is a key electron donor against oxidants. The GST superfamily is one of the major groups of enzymes widely expressed in organisms to protect cells from oxidative stress, cell imbalance and cell death [50,51]. Different aquatic animals showed diverse expression patterns of gst gene in response to hypoxia stress [52-55]. The results suggest that the regulation mechanism of glutathione metabolism in fish under hypoxic stress is complex and needs further study.

Ferroptosis is a common form of non-apoptotic regulated cell death, which was caused by different stimuli of stressor in animals [56]. Environmental stress leads to the occurrence of ferroptosis [21,50]. In this study, the ferroptosis pathway was significantly enriched in the reoxygen4h group. In this study, several up-regulated DEGs, such as glutathione genes ( $g c l m$, $g c l c$ and $g s s)$, transferrin $(t f)$, ferritin heavy 
chain (fth1) and heme oxygenase 1 (hmox1) involved in the ferroptosis process were identified in the reoxygen4h group. Genes involved in ferroptosis pathway, such as $t f$ and $g c l c$, were also significantly increased under environmental stress in other fish $[17,20]$. It implies that the changes in environmental stress can lead to the damage of animal tissues, which has adverse effects on the exchange of oxygen and ion functions.

Several differentially expressed genes involved in the regulation of the glycolysis process were significantly expressed in the hypoxialh group, such as pyruvate kinase $(p k)$, phosphofructokinase $(p f k)$, aldolase (aldo) and phosphoglycerate mutase (pgam) genes. The pk gene, a direct HIF-1 targeted gene, which was stimulated by the prolyl hydroxylase 3 (PHD3) [57] and involved in stress response of bacteria to hypoxia [58]. The aldo was involved in the mediated expression of HIF-1 gene under hypoxic stress [59]. The pgam gene was played a key role in the production of energy and biosynthesis of the organism, which is commonly expressed in the tumor cell [60]. Previous studies reported that the glycolysis process pathway was significantly enriched after exposure to the environmental stress in aquatic animals [61-65], indicating that this pathway plays an important role in participating in fish stress response.

\section{Conclusions}

This is the first transcriptome analysis to examine the gill response to hypoxia stress in S. sihama. The total number of up-regulated DEGs was found greater than the down-regulated DEGs with the increment of exposure time to hypoxia stress. In contrast, the number of down-regulated DEGs was found greater than up-regulated DEGs in the reoxygen treatment. Functional analysis of the DEGs showed that two GO terms and seven KEGG pathways were enriched. Our results provide a dataset to understand the regulatory mechanisms and molecular characteristics of hypoxia response in S. sihama.

Supplementary Materials: The following are available online at http://www.mdpi.com/2076-2615/10/4/628/s1, Figure S1: The KEGG pathway signification of differentially expressed genes (DEGs) comparison between groups. (A) hypoxia1h_vs_normoxia, (B) hypoxia4h_vs_normoxia, (C) reoxygen4h_vs_normoxia. The y-axis belongs to specific pathway, and the $x$-axis belongs to enrichment factor. The size and colors of the dots represent the number of genes and padj values, respectively (The dots with larger-size indicated a higher number of genes in the pathway). Table S1: The time points of experimental fish sampling under hypoxic stress and reoxygen condition. Table S2 Quantitative real time PCR (qRT-PCR) primer sequences data. Table S3: Annotation of top ten up- and down-regulated genes in the comparison between the groups in gill. (padj < 0.05). Table S4: Gene ontology (GO) of significantly genes up and down regulated differentially expressed genes (DEGs) comparison between treatment. Biological process (BP), cellular component (CC), and molecular function (MF), respectively.

Author Contributions: Conceptualization: W.S., C.T. and G.L.; data curation: W.S., C.T., J.Y., X.L. and F.H.; funding acquisition: C.T. and G.L.; methodology: W.S., J.Y., X.L. and F.H.; project administration: G.L.; resources: Y.H. and H.S.; supervision: G.L.; visualization: Y.Z.; writing-original draft: W.S. and C.T.; writing-review and editing: W.S., C.T. and G.L. All authors have read and agreed to the published version of the manuscript.

Funding: This study was supported by grants from the National Natural Science Foundation of China (Nos. 41706174 and 31702326), Natural Science Foundation of Guangdong Province (2016A030313743, 2017A030313101, 2018B030311050 and Edited based on previous published papers in the journal. 2019A1515010958), Independent Project of Guangdong Province Laboratory (ZJW-2019-06), the Department of Education of Guangdong Province (2018KQNCX111 and 2019KTSCX060) and Program for Scientific Research Start-up Funds of Guangdong Ocean University (R19026).

Conflicts of Interest: The authors declare no conflict of interest.

\section{References}

1. Rogers, N.J.; Urbina, M.A.; Reardon, E.E.; McKenzie, D.J.; Wilson, R.W. A new analysis of hypoxia tolerance in fishes using a database of critical oxygen level (Pcrit). Conserv. Physiol. 2016, 4, 1-19. [CrossRef] [PubMed]

2. Richards, J.G. Physiological, behavioral and biochemical adaptations of intertidal fishes to hypoxia. J. Exp. Biol. 2011, 214, 191-199. [CrossRef] [PubMed]

3. Turko, A.J.; Cooper, C.A.; Wright, P.A. Gill remodelling during terrestrial acclimation reduces aquatic respiratory function of the amphibious fish Kryptolebias marmoratus. J. Exp. Biol. 2012, 215, 3973-3980. [CrossRef] [PubMed] 
4. Mitrovic, D.; Dymowska, A.; Nilsson, G.E.; Perry, S.F. Physiological consequences of gill remodeling in goldfish (Carassius auratus) during exposure to long-term hypoxia. Am. J. Physiol. Regul. Integr. Comp. Physiol. 2009, 297, R224-R234. [CrossRef] [PubMed]

5. Choi, K.; Lehmann, D.W.; Harms, C.A.; Law, J.M. Acute hypoxia-reperfusion triggers immunocompromise in Nile Tilapia. J. Aquat. Anim. Health 2007, 19, 128-140. [CrossRef] [PubMed]

6. Onukwufor, J.O.; Wood, C.M. The osmorespiratory compromise in rainbow trout (Oncorhynchus mykiss): The effects of fish size, hypoxia, temperature and strenuous exercise on gill diffusive water fluxes and sodium net loss rates. Comp. Biochem. Physiol. Part A Mol. Integr. Physiol. 2018, 219-220, 10-18. [CrossRef] [PubMed]

7. Evans, D.H.; Piermarini, P.M.; Choe, K.P. The multifunctional fish gill: Dominant site of gas exchange, osmoregulation, acid-base regulation, and excretion of nitrogenous waste. Physiol. Rev. 2005, 85, 97-177. [CrossRef]

8. Wu, C. Bin; Liu, Z.Y.; Li, F.G.; Chen, J.; Jiang, X.Y.; Zou, S.M. Gill remodeling in response to hypoxia and temperature occurs in the hypoxia sensitive blunt snout bream (Megalobrama amblycephala). Aquaculture 2017, 479, 479-486. [CrossRef]

9. Sollid, J.; Nilsson, G.E. Plasticity of respiratory structures-Adaptive remodeling of fish gills induced by ambient oxygen and temperature. Respir. Physiol. Neurobiol. 2006, 154, 241-251. [CrossRef]

10. KAGA, T. Phylogenetic systematics of the family Sillaginidae (Percomorpha: Order Perciformes). Zootaxa 2013, 3642, 001-105. [CrossRef]

11. Tian, C.; Li, Z.; Dong, Z.; Huang, Y.; Du, T.; Chen, H.; Jiang, D.; Deng, S.; Zhang, Y.; Wanida, S.; et al. Transcriptome Analysis of Male and Female Mature Gonads of Silver Sillago (Sillago sihama). Genes 2019, 10, 129. [CrossRef] [PubMed]

12. FAO. The State of World Fisheries and Aquaculture 2018-Meeting the sustainable development goals; FAO: Rome, Italy, 2018; ISBN 9789251305621.

13. Yousif, O.; Menon, K.K.; A-Fatah, A.-R. Spawning, Larval Rearing and Growth of the Silver Sillago in Abu Dhabi. World Aquac. 2015, 46, 53-55.

14. Hrdlickova, R.; Toloue, M.; Tian, B. RNA-Seq methods for transcriptome analysis. Wiley Interdiscip. Rev. RNA 2017, 8, e1364. [CrossRef] [PubMed]

15. Qi, D.; Chen, Q.; Zheng, Z.; Wu, R.; Xia, M.; Chao, Y. Transcriptome Analysis Provides Insights Into the Adaptive Responses to Hypoxia of a Schizothoracine Fish (Gymnocypris eckloni). Front. Physiol. 2018, 9 , 1326. [CrossRef]

16. Hoff, M.L.M.; Fabrizius, A.; Czech-Damal, N.U.; Folkow, L.P.; Burmester, T. Transcriptome analysis identifies key metabolic changes in the hooded seal (Cystophora cristata) brain in response to hypoxia and reoxygenation. PLOS ONE 2017, 12, 1-21. [CrossRef]

17. Chen, B.X.; Yi, S.K.; Wang, W.F.; He, Y.; Huang, Y.; Gao, Z.X.; Liu, H.; Wang, W.M.; Wang, H.L. Transcriptome comparison reveals insights into muscle response to hypoxia in blunt snout bream (Megalobrama amblycephala). Gene 2017, 624, 6-13. [CrossRef]

18. Geng, X.; Feng, J.; Liu, S.; Wang, Y.; Arias, C.; Liu, Z. Transcriptional regulation of hypoxia inducible factors alpha (HIF- $\alpha$ ) and their inhibiting factor (FIH-1) of channel catfish (ictalurus punctatus) under hypoxia. Comp. Biochem. Physiol. B Biochem. Mol. Biol. 2014, 169, 38-50. [CrossRef]

19. Liao, X.; Cheng, L.; Xu, P.; Lu, G.; Wachholtz, M.; Sun, X.; Chen, S. Transcriptome Analysis of Crucian Carp (Carassius auratus), an Important Aquaculture and Hypoxia-Tolerant Species. PLoS ONE 2013, 8, 1-11. [CrossRef]

20. Zhou, T.; Gui, L.; Liu, M.; Li, W.; Hu, P.; Duarte, D.F.C.; Niu, H.; Chen, L. Transcriptomic responses to low temperature stress in the Nile tilapia, Oreochromis niloticus. Fish Shellfish Immunol. 2019, 84, 1145-1156. [CrossRef]

21. Long, Y.; Yan, J.; Song, G.; Li, X.; Li, X.; Li, Q.; Cui, Z. Transcriptional events co-regulated by hypoxia and cold stresses in Zebrafish larvae. BMC Genomics 2015, 16, 385. [CrossRef]

22. Olsvik, P.A.; Vikeså, V.; Lie, K.K.; Hevrøy, E.M. Transcriptional responses to temperature and low oxygen stress in Atlantic salmon studied with next-generation sequencing technology. BMC Genomics 2013, 14, 817. [CrossRef] [PubMed]

23. Trapnell, C.; Williams, B.A.; Pertea, G.; Mortazavi, A.; Kwan, G.; van Baren, M.J.; Salzberg, S.L.; Wold, B.J.; Pachter, L. Transcript assembly and quantification by RNA-Seq reveals unannotated transcripts and isoform switching during cell differentiation. Nat. Biotechnol. 2010, 28, 511. [CrossRef] [PubMed] 
24. Varet, H.; Brillet-Guéguen, L.; Coppée, J.Y.; Dillies, M.A. SARTools: A DESeq2- and edgeR-based R pipeline for comprehensive differential analysis of RNA-Seq data. PLoS ONE 2016, 11, 1-8. [CrossRef] [PubMed]

25. Anders, S.; Huber, W. Differential expression analysis for sequence count data. Genome Biol. 2010, 11, R106. [CrossRef]

26. ZHANG, N.; DU, W.; WANG, Z.; HUANG, Y.; DU, T.; DONG, Z. Screening of Reference Genes for Real-time PCR in Different Tissues from Sillago sihama. J. Guangdong Ocean Univ. 2018, 38.

27. Livak, K.J.; Schmittgen, T.D. Analysis of relative gene expression data using real-time quantitative PCR and the 2- $\Delta \Delta \mathrm{CT}$ method. Methods 2001, 25, 402-408. [CrossRef]

28. Khansari, A.R.; Balasch, J.C.; Vallejos-Vidal, E.; Parra, D.; Reyes-López, F.E.; Tort, L. Comparative Immuneand Stress-Related Transcript Response Induced by Air Exposure and Vibrio anguillarum Bacterin in Rainbow Trout (Oncorhynchus mykiss) and Gilthead Seabream (Sparus aurata) Mucosal Surfaces. Front. Immunol. 2018, 9, 856. [CrossRef]

29. Liu, Y.; Xin, Z.Z.; Zhang, D.Z.; Wang, Z.F.; Zhu, X.Y.; Tang, B.P.; Jiang, S.H.; Zhang, H. Bin; Zhou, C.L.; Chai, X.Y.; et al. Transcriptome analysis of yellow catfish (Pelteobagrus fulvidraco) liver challenged with polyriboinosinic polyribocytidylic acid (poly I:C). Fish Shellfish Immunol. 2017, 68, 395-403. [CrossRef]

30. Jin, J.; Wang, Y.; Wu, Z.; Hergazy, A.; Lan, J.; Zhao, L.; Liu, X.; Chen, N.; Lin, L. Transcriptomic analysis of liver from grass carp (Ctenopharyngodon idellus) exposed to high environmental ammonia reveals the activation of antioxidant and apoptosis pathways. Fish Shellfish Immunol. 2017, 63, 444-451. [CrossRef]

31. Xiao, W. The hypoxia signaling pathway and hypoxic adaptation in fishes. Sci. China Life Sci. 2015, 58, 148-155. [CrossRef]

32. Chen, N.; Huang, C.H.; Chen, B.X.; Liu, H.; Wang, W.M.; Gul, Y.; Wang, H.L. Alternative splicing transcription of Megalobrama amblycephala HIF prolyl hydroxylase PHD3 and up-regulation of PHD3 by HIF-1 $\alpha$. Biochem. Biophys. Res. Commun. 2016, 469, 737-742. [CrossRef] [PubMed]

33. Sahlmann, C.; Sutherland, B.J.G.; Kortner, T.M.; Koop, B.F.; Krogdahl, Å.; Bakke, A.M. Early response of gene expression in the distal intestine of Atlantic salmon (Salmo salar L.) during the development of soybean meal induced enteritis. Fish Shellfish Immunol. 2013, 34, 599-609. [CrossRef] [PubMed]

34. Long, M.; Zhao, J.; Li, T.; Tafalla, C.; Zhang, Q.; Wang, X.; Gong, X.; Shen, Z.; Li, A. Transcriptomic and proteomic analyses of splenic immune mechanisms of rainbow trout (Oncorhynchus mykiss) infected by Aeromonas salmonicida subsp. salmonicida. J. Proteomics 2015, 122, 41-54. [CrossRef] [PubMed]

35. Krücken, J.; Schroetel, R.M.U.; Müller, I.U.; Saïdani, N.; Marinovski, P.; Benten, W.P.M.; Stamm, O.; Wunderlich, F. Comparative analysis of the human gimap gene cluster encoding a novel GTPase family. Gene 2004, 341, 291-304. [CrossRef]

36. Huang, Z.; Zhang, W.; Gao, C.; Ji, B.; Chi, X.; Zheng, W.; Wang, H.L. Dysregulation of GTPase IMAP family members in hepatocellular cancer. Mol. Med. Rep. 2016, 14, 4119-4123. [CrossRef]

37. Råbergh, C.M.I.; Vrolijk, N.H.; Lipsky, M.M.; Chen, T.T. Differential expression of two CYP1A genes in rainbow trout (Oncorhynchys mykiss). Toxicol. Appl. Pharmacol. 2000, 165, 195-205. [CrossRef]

38. Leiva, K.; Werner, N.; Sepúlveda, D.; Barahona, S.; Baeza, M.; Cifuentes, V.; Alcaíno, J. Identification and functional characterization of the CYP51 gene from the yeast Xanthophyllomyces dendrorhous that is involved in ergosterol biosynthesis. BMC Microbiol. 2015, 15, 89. [CrossRef]

39. Liu, J.; Tian, Y.; Ding, Y.; Heng, D.; Xu, K.; Liu, W.; Zhang, C. Role of CYP51 in the regulation of T3 and FSH-induced steroidogenesis in female mice. Endocrinology 2017, 158, 3974-3987. [CrossRef]

40. Morrison, A.M.S.; Goldstone, J.V.; Lamb, D.C.; Kubota, A.; Lemaire, B.; Stegeman, J.J. Identification, modeling and ligand affinity of early deuterostome CYP51s, and functional characterization of recombinant zebrafish sterol $14 \alpha$-demethylase. Biochim. Biophys. Acta Gen. Subj. 2014, 1840, 1825-1836. [CrossRef]

41. Weber, G.J.; Choe, S.E.; Dooley, K.A.; Paffett-Lugassy, N.N.; Zhou, Y.; Zon, L.I. Mutant-specific gene programs in the zebrafish. Blood 2005, 106, 521-530. [CrossRef]

42. Qian, L.; Qi, S.; Cao, F.; Zhang, J.; Li, C.; Song, M.; Wang, C. Effects of penthiopyrad on the development and behaviour of zebrafish in early-life stages. Chemosphere 2019, 214, 184-194. [CrossRef] [PubMed]

43. Kumar, A.; Estrada, D.F. Specificity of the Redox Complex between Cytochrome P450 24 A1 and adrenodoxin relies on carbon-25 hydroxylation of vitamin-D Substrate. Drug Metab. Dispos. 2019, 47, 974-982. [CrossRef] [PubMed] 
44. Chun, R.F.; Blatter, E.; Elliott, S.; Fitz-gibbon, S.; Rieger, S.; Sagasti, A.; Adams, J.S.; Hewison, M. Cloning of a functional 25-hydroxy vitamin D-1 $\alpha$-hydroxylase in zebra fish (Danio rerio). Cell Biochem. Funct. 2014, 675-682. [CrossRef] [PubMed]

45. Li, H.; Li, Y.; Lu, J.W.; Huo, X.; Gong, Z. Liver-specific androgen receptor knockout attenuates early liver tumor development in zebrafish. Sci. Rep. 2019, 9, 1-11. [CrossRef] [PubMed]

46. Rahman, M.S.; Thomas, P. Effects of hypoxia exposure on hepatic cytochrome P450 1A (CYP1A) expression in atlantic croaker: Molecular mechanisms of CYP1A down-regulation. PLoS ONE 2012, 7, e40825. [CrossRef] [PubMed]

47. Alak, G.; Yeltekin, A.Ç.; Tas, I.H.; Ucar, A.; Parlak, V.; Topal, A.; Kocaman, E.M.; Atamanalp, M. Investigation of 8-OHdG, CYP1A, HSP70 and transcriptional analyses of antioxidant defence system in liver tissues of rainbow trout exposed to eprinomectin. Fish Shellfish Immunol. 2017, 65, 136-144. [CrossRef]

48. Leveelahti, L.; Leskinen, P.; Leder, E.H.; Waser, W.; Nikinmaa, M. Responses of threespine stickleback (Gasterosteus aculeatus, L) transcriptome to hypoxia. Comp. Biochem. Physiol. Part D Genomics Proteomics 2011, 6, 370-381. [CrossRef]

49. Zhang, X. Bin; Zeng, Y.M.; Chen, X.Y.; Zhang, Y.X.; Ding, J.Z.; Xue, C. Decreased expression of hepatic cytochrome P450 1A2 (CYP1A2) in a chronic intermittent hypoxia mouse model. J. Thorac. Dis. 2018, 10, 825-834. [CrossRef]

50. Al Tameemi, W.; Dale, T.P.; Al-Jumaily, R.M.K.; Forsyth, N.R. Hypoxia-modified cancer cell metabolism. Front. Cell Dev. Biol. 2019, 7, 1-15. [CrossRef]

51. Strange, R.C.; Spiteri, M.A.; Ramachandran, S.; Fryer, A.A. Glutathione-S-transferase family of enzymes. Mutat. Res. Fundam. Mol. Mech. Mutagen. 2001, 482, 21-26. [CrossRef]

52. Sun, S.; Xuan, F.; Fu, H.; Ge, X.; Zhu, J.; Qiao, H.; Jin, S.; Zhang, Y. Comparative proteomic study of the response to hypoxia in the muscle of oriental river prawn (Macrobrachium nipponense). J. Proteomics 2016, 138, 115-123. [CrossRef] [PubMed]

53. Wang, L.; Zhang, G.; Chen, J.; Mao, J.; Liang, F.; Yin, S.; Tang, Z.; Zhao, C.; Chen, S. Modulated expression and enzymatic activities of darkbarbel catfish, pelteobagrus vachelli for oxidative stress induced by acute hypoxia and reoxygenation. Chemosphere 2016, 151, 271-279.

54. Wu, F.; Zheng, Y.; Gao, J.; Chen, S.; Wang, Z. Induction of oxidative stress and the transcription of genes related to apoptosis in rare minnow (Gobiocypris rarus) larvae with aroclor 1254 exposure. Ecotoxicol. Environ. Saf. 2014, 110, 254-260. [CrossRef] [PubMed]

55. Olsvik, P.A.; Nordtug, T.; Altin, D.; Lie, K.K.; Overrein, I.; Hansen, B.H. Transcriptional effects on glutathione S-transferases in first feeding Atlantic cod (Gadus morhua) larvae exposed to crude oil. Chemosphere 2010, 79, 905-913. [CrossRef]

56. Yang, M.; Chen, P.; Liu, J.; Zhu, S.; Kroemer, G.; Klionsky, D.J.; Lotze, M.T.; Zeh, H.J.; Kang, R.; Tang, D. Clockophagy is a novel selective autophagy process favoring ferroptosis. Sci. Adv. 2019, 5, eaaw2238. [CrossRef]

57. Luo, W.; Hu, H.; Chang, R.; Zhong, J.; Knabel, M.; O’Meally, R.; Cole, R.N.; Pandey, A.; Semenza, G.L. Pyruvate kinase M2 is a PHD3-stimulated coactivator for hypoxia-inducible factor 1. Cell 2011, 145, 732-744. [CrossRef]

58. Zhong, W.; Guo, J.; Cui, L.; Chionh, Y.H.; Li, K.; El Sahili, A.; Cai, Q.; Yuan, M.; Michels, P.A.M.; Fothergill-Gilmore, L.A.; et al. Pyruvate kinase regulates the pentose-phosphate pathway in response to hypoxia in Mycobacterium tuberculosis. J. Mol. Biol. 2019, 431, 3690-3705. [CrossRef]

59. Ifeanyi, O.E. Hypoxia and enzyme metabolism: A Review. 2014, 5, 40-43.

60. Xu, Y.; Li, F.; Lv, L.; Li, T.; Zhou, X.; Deng, C.-X.; Guan, K.-L.; Lei, Q.-Y.; Xiong, Y. Oxidative stress activates SIRT2 to deacetylate and stimulate phosphoglycerate mutase. Cancer Res. 2014, 74, 3630-3642. [CrossRef]

61. Nitzan, T.; Kokou, F.; Doron-Faigenboim, A.; Slosman, T.; Biran, J.; Mizrahi, I.; Zak, T.; Benet, A.; Cnaani, A. Transcriptome analysis reveals common and differential response to low temperature exposure between tolerant and sensitive blue tilapia (Oreochromis aureus). Front. Genet. 2019, 10, 1-11. [CrossRef]

62. Martínez, M.L.; Landry, C.; Boehm, R.; Manning, S.; Cheek, A.O.; Rees, B.B. Effects of long-term hypoxia on enzymes of carbohydrate metabolism in the gulf killifish, Fundulus grandis. J. Exp. Biol. 2006, 209, 3851-3861. [CrossRef] [PubMed]

63. Lushchak, V.I.; Bahnjukova, T.V.; Storey, K.B. Effect of hypoxia on the activity and binding of glycolytic and associated enzymes in sea scorpion tissues. Brazilian J. Med. Biol. Res. 1998, 31, 1059-1067. [CrossRef] 
64. Cota-Ruiz, K.; Leyva-Carrillo, L.; Peregrino-Uriarte, A.B.; Valenzuela-Soto, E.M.; Gollas-Galván, T.; Gómez-Jiménez, S.; Hernández, J.; Yepiz-Plascencia, G. Role of HIF-1 on phosphofructokinase and fructose 1, 6-bisphosphatase expression during hypoxia in the white shrimp Litopenaeus vannamei. Comp. Biochem. Physiol. Part A Mol. Integr. Physiol. 2016, 198, 1-7. [CrossRef] [PubMed]

65. Aliparasti, M.R.; Alipour, M.R.; Almasi, S.; Feizi, H. Effect of ghrelin on aldolase gene expression in the heart of chronic hypoxic rat. Int. J. Endocrinol. Metab. 2012, 10, 553-557. [CrossRef] [PubMed] 